\title{
Effect of Platelet-Rich Plasma on the Healing of Intrabony Defects Treated With an Anorganic Bovine Bone Mineral: A Pilot Study
}

\author{
Ferenc Döri, * Viola Kovács, ${ }^{*}$ Nicole B. Arweiler, ${ }^{\dagger}$ Tamás Huszár, ${ }^{\dagger}$ István Gera,*
} Dimitris Nikolidakis, $₫$ and Anton Sculean $\S$

Background: Periodontal therapy using the combination of platelet-rich plasma (PRP) and different grafting materials has been suggested as a modality to enhance the outcome of regenerative surgery. In most clinical studies, a barrier membrane was used to cover the defects, and thus, the effects of PRP may have been masked by the effects of the barrier. The data from controlled clinical studies evaluating the effect of regenerative therapy using various grafting materials with or without PRP are still limited. The purpose of this study was to clinically compare the healing of intrabony defects treated with either a combination of an anorganic bovine bone mineral (ABBM) and PRP to those obtained with ABBM alone.

Methods: Thirty patients with advanced chronic periodontal disease and displaying one intrabony defect were randomly treated with PRP + ABBM or ABBM alone. The following clinical parameters were evaluated at baseline and 1 year after treatment: plaque index (PI), gingival index (GI), bleeding on probing (BOP), probing depth (PD), gingival recession (GR), and clinical attachment level (CAL). The primary outcome variable was CAL.

Results: No statistical significant differences in any of the investigated parameters between the two groups were observed at baseline. Healing was uneventful in all patients. In the PRP + ABBM group, mean PD decreased from $8.6 \pm 1.8 \mathrm{~mm}$ to $3.4 \pm 1.4 \mathrm{~mm}(P<0.001)$ and mean CAL changed from $9.9 \pm 1.7 \mathrm{~mm}$ to $5.3 \pm 1.8 \mathrm{~mm}(P<0.001)$. In the ABBM group, mean PD decreased from $8.5 \pm 2.0 \mathrm{~mm}$ to $3.2 \pm 1.3 \mathrm{~mm}(P<0.001)$ and mean CAL changed from $9.6 \pm 1.9 \mathrm{~mm}$ to $4.9 \pm 1.5 \mathrm{~mm}(P<0.001)$. CAL gains $\geq 3 \mathrm{~mm}$ were measured in $80 \%$ (12 of 15 defects) of cases treated with PRP + ABBM and in 87\% (13 of 15 defects) of cases treated with ABBM alone. No statistically significant differences in any of the investigated parameters were observed between the two groups at the 1-year reevaluation.

Conclusions: Within the limits of the present study, it can be concluded that 1 ) at 1 year after regenerative surgery with PRP + ABBM and ABBM alone, significant PD reductions and CAL gains were found, and 2) the use of PRP failed to improve the results obtained with ABBM alone. J Periodontol 2009;80:1599-1605.

\section{KEY WORDS}

Bone graft(s); clinical trial(s); periodontal regeneration; periodontitis; platelet-rich plasma; wound healing.

\footnotetext{
* Department of Periodontology, Semmelweis University, Budapest, Hungary.

$\dagger$ Department of Operative Dentistry and Periodontology, University of Freiburg, Germany.

* Department of Oral and Maxillofacial Surgery, Semmelweis University.

$\S$ Department of Periodontology, University of Bern, Bern, Switzerland.
}

$\mathrm{R}$ egenerative periodontal therapy aims to reconstruct the toothsupporting tissues (i.e., root cementum, periodontal ligament, and alveolar bone), which have been lost due to periodontitis or trauma. ${ }^{1}$ Polypeptide growth factors have been shown to play a crucial role in the growth and differentiation of cells involved in periodontal wound healing. ${ }^{2-8}$ In humans, regenerative surgery using recombinant human platelet-derived growth factorBB (rhPDGF-BB) on a beta-tricalcium phosphate $(\beta-\mathrm{TCP})$ vehicle or combined with demineralized freeze-dried bone allograft (DFDBA) resulted in robust regeneration of cementum, periodontal ligament, and bone. ${ }^{9,10}$ Furthermore, data from controlled clinical trials ${ }^{11,12}$ have shown that regenerative periodontal surgery using rhPDGF-BB and recombinant human insulin-like growth factor-I or rhPDGF-BB on a $\beta$-TCP vehicle resulted in significantly

doi: 10.1902/jop.2009.090058 
higher improvements in terms of defect fill and gain of clinical attachment level (CAL) compared to controls (i.e., surgery and application of the vehicle or surgery alone). Platelet-rich plasma (PRP) is an autologous volume of plasma with a four- to five-fold increased platelet concentration above baseline and a well-documented source of growth factors, which has been used to improve wound healing and to increase the rate of bone deposition and bone volume in combination with bone grafts during bone augmentation procedures. ${ }^{13-15}$ The positive effects of PRP on bone healing could be attributed to the angiogenetic, proliferative, and differentiating effects on osteoblasts of transforming growth factor (TGF) $\beta$ and PDGF that are present in PRP in high concentrations. ${ }^{16} \mathrm{PRP}$ combined with different grafting materials, barrier membranes, or an enamel matrix protein derivative has also been used in regenerative periodontal therapy with varying degrees of success. ${ }^{17-29}$ In most studies, ${ }^{18-20,27-29}$ a barrier membrane was used to cover the defects, and thus, the effects of PRP may have been masked by the effects of the barrier. However, the data from controlled clinical studies evaluating the additional effect of PRP when used in combination with different grafting materials are also somewhat controversial. Although some studies ${ }^{21-23}$ have indicated significantly higher improvements in terms of probing depth (PD) reduction and CAL when PRP was combined with a grafting material, others ${ }^{24-26}$ have failed to demonstrate significant differences.

A very well-documented grafting material that is widely used for regenerative periodontal treatment, ridge augmentation, and sinus-floor elevation is anorganic bovine bone mineral (ABBM). ${ }^{30-37}$ Human histologic studies ${ }^{31,37}$ have provided evidence for periodontal regeneration following treatment of intrabony defects with $A B B M$ alone. In intrabony defects, treatment with ABBM or DFDBA resulted in comparable clinical outcomes. ${ }^{32}$ Thus, due to its excellent biologic properties and the human histologic evidence suggesting a potential for promoting periodontal wound healing and regeneration, ABBM is one of the most frequently used grafting materials in reconstructive periodontal surgery. ${ }^{30-37}$ However, at present, there are still limited data on the potential effects of PRP used in combination with ABBM.

Thus, the aim of this prospective controlled, clinical study was to compare the healing of intrabony defects treated with a combination of ABBM + PRP or ABBM alone.

\section{MATERIALS AND METHODS}

\section{Patient Population}

Thirty patients (21 females and nine males; age range: 28 to 65 years) were included in this study. There were no differences in the age distribution between the two groups. All patients suffered from generalized severe chronic periodontal disease. ${ }^{38}$ Chronic periodontitis was classified as generalized when $>30 \%$ of sites were affected by a clinical attachment loss $\geq 5 \mathrm{~mm} .{ }^{38}$ The study had a parallel-arm design including two treatment groups. Fifteen patients were recruited in each group (i.e., test and control groups) after having signed an informed consent. The study was performed in accordance with the Helsinki Declaration of 1975, as revised in 2000. The study protocol was reviewed and approved by the ethical board at Semmelweis University. All patients were treated at the Department of Periodontology, Semmelweis University, by the same experienced surgeon (FD) between June 2006 and May 2007.

The enrolled patients met the following inclusion criteria: 1) no systemic diseases which could influence the outcome of the therapy; 2) a good level of oral hygiene (plaque index $[\mathrm{PI}]<1$ ); ${ }^{39} 3$ ) compliance with the maintenance program; 4 ) presence of one intrabony defect with PD $\geq 6 \mathrm{~mm}$ and an intrabony component (INTRA) $\geq 3 \mathrm{~mm}$ as detected on radiographs and measured at bone sounding; 5) no intrabony defects extending into a furcation area; and 6) no teeth presenting furcation involvements. None of the patients were a smoker. ${ }^{40}$ The following clinical parameters were assessed 1 week prior to and 1 year after the surgical procedure using the same type of periodontal probe: ${ }^{\mathrm{PI}},{ }^{39}$ gingival index (GI), ${ }^{39}$ bleeding on probing (BOP) assessed dichotomously, $\mathrm{PD}$, gingival recession (GR), and CAL. The measurements were made at six sites per tooth (mesio-facial, mid-facial, disto-facial, mesio-lingual, mid-lingual, and disto-lingual) by a calibrated investigator (IG). The examiner was not aware of the type of treatment rendered. The cemento-enamel junction (CEJ) was used as the reference point. In cases where the CEJ was not visible, a restoration margin was used for these measurements. Pre- and postoperative non-standardized radiographs were taken with the long-cone parallel technique. Additionally, in all cases, the precise position of the periodontal probe was recorded using intraoral photographs taken at the same magnification and from the same position. The deepest point of baseline defects was included in the calculations.

\section{Randomization}

Using a randomized block approach, the defects were randomly assigned before surgery to the two treatment groups. Blocking to control for the effects of the prognostic variables, the distance from the alveolar bone crest to the bottom of the defect (INTRA) and CAL were used to decrease outcome variability. ${ }^{41}$ The INTRA was estimated before surgery based on radiographs and transgingival bone-sounding recordings

|| UNC-15, Hu-Friedy, Chicago, IL. 
by the same calibrated investigator (IG) who also performed all other clinical measurements.

\section{Intraexaminer Reproducibility}

Five patients, each showing 10 teeth (single and multi-rooted) with PDs $>6 \mathrm{~mm}$ on at least one aspect of each tooth, were used to calibrate the examiner. The examiner evaluated the patients on two separate occasions, 48 hours apart. Calibration was accepted if $>90 \%$ of the recordings could be reproduced within a 1.0-mm difference.

\section{PRP Preparation}

The PRP preparation was performed by using a standardized kit il immediately prior to surgery. The employed system consists of a standard laboratory centrifuge with eight monovettes, a shaker, and a kit with disposable material. One monovette was filled with $8.5 \mathrm{ml}$ solution $(8 \mathrm{ml}$ blood and $0.5 \mathrm{ml}$ citrate-phosphate-dextrose-adenine solution for anticoagulation). The first spin was performed at 2,400 revolutions per minute (rpm) for 10 minutes. This procedure divided the blood into three basic components: red blood cells, PRP, and platelet-poor plasma (PPP). The red blood cell layer formed at the lowest level, the PRP layer formed in the middle, and the PPP layer formed at the top. PRP and PPP were collected in a second monovette. A second spin was performed at 3,600 rpm for 15 minutes The platelet pellet concentrated at the bottom of the monovette, whereas the PPP concentrated on the top. The PPP was removed so that only PRP remained in the monovette. After resuspending the platelet pellet within the remaining volume of plasma in the shaker, a $0.4-\mathrm{ml}$ volume of PRP was produced.

\section{Surgical Procedure}

Following local anesthesia, intracrevicular incisions were made, and mucoperiosteal flaps were raised vestibularly and orally. For better access to the surgical site or to achieve better closure, the flap was extended one or two teeth mesially or distally in most cases. Vertical releasing incisions were performed when deemed necessary. The granulation tissue was removed from the defects, and the roots were thoroughly scaled and planed by means of hand and ultrasonic instruments. No conditioning of the root surfaces was performed. During surgery, the following measurements were made: the distance from the CEJ to the bottom of the defect (CEJ-BD) and the distance from the CEJ to the most coronal extension of the alveolar bone crest (CEJ-BC). The INTRA of the defects was defined as CEJ-BD - CEJ-BC.

In the test group (PRP + ABBM), at the time of application, PRP was first activated after combination with an equal volume of a sterile saline solution containing $10 \%$ calcium chloride and $100 \mathrm{U} / \mathrm{ml}$ sterile thrombin. Within a few seconds, the PRP displayed a sticky consistency. Afterwards, ABBM $^{\#}$ granules (particle size, 0.25 to $1.0 \mathrm{~mm}$ ) were mixed with the coagulated PRP. Care was taken not to overfill the defects. The same surgical protocol was also used for the control sites (ABBM alone) with the exception of using PRP. Finally, the flaps were coronally advanced and closed with vertical or horizontal mattress sutures.

\section{Postoperative Care}

All patients received antibiotics for 1 week $(3 \times 500$ $\mathrm{mg}$ amoxicillin/day). Postoperative care consisted of $0.2 \%$ chlorhexidine rinses twice a day for 4 weeks. Sutures were removed 14 days after the surgery. Recall appointments were scheduled weekly during the first 6 weeks after surgery and once per month following the rest of the observation period of 1 year. The recall appointments mainly consisted of reinforcement of oral hygiene measures and professional supragingival tooth cleaning.

\section{Statistical Analyses}

Statistical analyses were performed using a commercially available software program.**

The primary outcome variable was CAL. For the statistical evaluation of the changes from baseline to 1 year in each treatment group, the paired $t$ test was used. For the comparisons between the groups, the unpaired $t$ test was used. The $\alpha$ error was set at 0.05 . The power of the study, given $\geq 1 \mathrm{~mm}$ as a significant difference between the groups, was calculated to be 0.80 .

\section{RESULTS}

The postoperative healing was uneventful in all cases. No complications, such as allergic reactions, abscesses, or infections, were observed throughout the study period. All patients complied with the monthly recall appointments throughout the 1-year study period. No dropouts occurred.

There were minor differences in the gender distribution between the groups (i.e., five males in the test group and four males in control group). Table 1 illustrates the mean PI, GI, and BOP for both groups. GI and BOP improved statistically significantly compared to baseline, but no statistically significant differences were found between the two groups.

The defects displayed a comparable distribution and configuration in the two groups (Table 2). The depth of the INTRA as measured during surgery is presented in Table 3. There were no differences in the depth of the INTRA between the two groups.

\footnotetext{
I Curasan PRP kit, Curasan, Kleinostheim, Germany.

\# Bio-Oss, Geistlich, Wolhusen, Switzerland.

** SPSS for Windows (2003), SPSS, Chicago, IL.
} 
Table I.

\section{PI, GI, and BOP Scores at Baseline and 1 Year}

\begin{tabular}{lccc}
\hline Parameter & $\begin{array}{c}\text { PRP }+ \text { ABBM } \\
(n=15)\end{array}$ & $\begin{array}{c}\text { ABBM } \\
(n=15)\end{array}$ & $P$ Value \\
\hline PI (mean \pm SD) & & & \\
Baseline & $0.8 \pm 0.1$ & $0.7 \pm 0.1$ & NS \\
I year & $0.7 \pm 0.2$ & $0.6 \pm 0.2$ & NS \\
P value & NS & NS & \\
GI (mean \pm SD) & & & \\
Baseline & $1.2 \pm 0.2$ & $1.3 \pm 0.3$ & NS \\
I year & $0.6 \pm 0.1$ & $0.7 \pm 0.4$ & NS \\
$P$ value & $<0.05$ & $<0.05$ & \\
BOP (\%) & & & \\
Baseline & 43 & 42 & NS \\
I year & 15 & 13 & $N S$ \\
$P$ value & $<0.05$ & $<0.05$ & \\
\hline
\end{tabular}

$\mathrm{NS}=$ not statistically significant.

Table 2.

\section{Distribution and Configuration of Treated Defects}

\begin{tabular}{lcc}
\hline Defect Location & $\begin{array}{c}\text { PRP }+ \text { ABBM } \\
(n=15)\end{array}$ & $\begin{array}{c}\text { ABBM } \\
(n=15)\end{array}$ \\
\hline Maxilla & 10 & 8 \\
Mandible & 5 & 7 \\
Anterior teeth & 0 & 2 \\
Premolars & 4 & 3 \\
Molars & 11 & 10 \\
Combined I- and 2-wall & 9 & 9 \\
2-wall & 6 & 6 \\
\hline
\end{tabular}

At baseline, no statistically significant differences were found between the two groups for mean PD, GR, and CAL (Table 4). At 1 year, mean PD decreased significantly in both groups $(P<0.001)$ compared to baseline, but no statistically significant difference between the groups was found (Table 4). Mean GR increased significantly, in both groups $(P<0.01)$ compared to baseline, but no statistically significant difference between the groups was found (Table 4). In both groups, mean CAL improved significantly compared to baseline $(P<0.001)$ without a statistically significant difference between the groups (Table 4).

At baseline, the mean GR was $1.3 \pm 1.1 \mathrm{~mm}$ in the $\mathrm{PRP}+\mathrm{ABBM}$ group and $1.1 \pm 0.9 \mathrm{~mm}$ in the ABBM group, with no statistically significant difference between the groups (Table 4). At 1 year, the mean GR measured $1.9 \pm 1.8 \mathrm{~mm}$ in the ABBM + PRP group and $1.7 \pm 1.5 \mathrm{~mm}$ in the ABBM group. Compared to baseline, the changes in GR were statistically significant for both groups $(P<0.01)$ without a statistically significant difference between the groups.

At baseline, the mean CAL was $9.9 \pm 1.7 \mathrm{~mm}$ in the PRP + ABBM group and $9.6 \pm 1.9 \mathrm{~mm}$ in the ABBM group. No statistically significant difference was found between the groups. At 1 year, the mean CAL was $5.3 \pm$ $1.8 \mathrm{~mm}$ in the PRP + ABBM group and $4.9 \pm 1.5 \mathrm{~mm}$ in the ABBM group (Table 4). Mean CAL gain was $4.6 \pm$ $1.7 \mathrm{~mm}$ in the PRP + ABBM group and $4.7 \pm 1.6 \mathrm{~mm}$ in the ABBM group. In both groups, CAL improved significantly compared to baseline $(P<0.001)$ without a statistically significant difference between the groups.

At 1 year, CAL gains $\geq 3 \mathrm{~mm}$ were measured in $80 \%$ (12 of 15 defects) of the cases treated with PRP + ABBM and $87 \%$ (13 of 15 defects) of the cases treated with $\mathrm{ABBM}$ alone.

\section{DISCUSSION}

The results of the present study indicated that significant clinical improvements can be obtained in deep intrabony defects following treatment with PRP + $A B B M$ and ABBM alone. However, no significant differences in any of the investigated parameters were found between the two treatments. The observation that all used materials were very well tolerated without any signs of allergic reactions, flap necrosis, or rejection of the implanted materials is in line with previous reports. ${ }^{17-37,42,43}$ The finding that regenerative surgery with PRP + ABBM may result in significant clinical improvements corroborates previously published data. ${ }^{20,21}$ In a controlled clinical study ${ }^{21}$ using a comparable design to that employed in the present trial, at 6 months following surgery, both approaches yielded significant clinical improvements compared to baseline, although the PRP enhanced group resulted in significantly higher outcomes in terms of PD reduction and CAL gain compared to those obtained with the graft alone. In that study, mean CAL gain measured $3.15 \mathrm{~mm}$ in the PRP + ABBM group and $2.31 \mathrm{~mm}$ in the ABBM group, respectively, whereas CAL gains $\geq 3 \mathrm{~mm}$ were obtained in $77 \%$ of the PRP enhanced group versus $38.8 \%$ in the group treated with the graft alone. ${ }^{21}$ These values are lower compared to those obtained in the present study, where mean CAL gain measured $4.6 \pm 1.7 \mathrm{~mm}$ in the PRP + ABBM group and $4.7 \pm 1.6 \mathrm{~mm}$ in the ABBM group, whereas CAL gains $\geq 3 \mathrm{~mm}$ were obtained in $80 \%$ of the defects treated with PRP + ABBM and $87 \%$ of the defects treated with ABBM alone. Possible explanations for this discrepancy might be related to differences in terms of study design, initial defect depth, and intrabony defect 
Table 3.

Baseline Defect Characteristics ( $\mathrm{mm}$; mean \pm SD)

\begin{tabular}{lccccc}
\hline Treatment & PD & CAL & CEJ-BD & CEJ-BC & INTRA \\
\hline PRP + ABBM $(n=15)$ & $8.6 \pm 1.8$ & $9.9 \pm 1.7$ & $11.0 \pm 1.8$ & $5.9 \pm 1.7$ & $5.1 \pm 1.7$ \\
ABBM $(n=15)$ & $8.5 \pm 2.0$ & $9.6 \pm 1.9$ & $10.8 \pm 2.0$ & $5.8 \pm 1.8$ & $5.0 \pm 1.9$ \\
$P$ value & NS & NS & NS & NS & NS \\
\hline
\end{tabular}

NS $=$ not statistically significant.

\section{Table 4.}

Clinical Parameters $(\mathrm{mm}$; mean $\pm \mathrm{SD})$ at Baseline and 1 Year ( $\mathrm{n}=15$ for each group)

\begin{tabular}{lcccc}
\hline $\begin{array}{l}\text { Clinical } \\
\text { Parameter }\end{array}$ & Baseline & I Year & Difference & $P$ Value \\
\hline PD & & & & \\
PRP + ABBM & $8.6 \pm 1.8$ & $3.4 \pm 1.4$ & $5.2 \pm 1.6$ & $<0.001$ \\
ABBM & $8.5 \pm 2.0$ & $3.2 \pm 1.3$ & $5.3 \pm 1.7$ & $<0.001$ \\
$P$ value & $\mathrm{NS}$ & $\mathrm{NS}$ & $\mathrm{NS}$ & \\
GR & & & & \\
PRP + ABBM & $1.3 \pm 1.1$ & $1.9 \pm 1.8$ & $0.6 \pm 1.7$ & $<0.01$ \\
ABBM & $1.1 \pm 0.9$ & $1.7 \pm 1.5$ & $0.6 \pm 1.6$ & $<0.01$ \\
$P$ value & $\mathrm{NS}$ & $\mathrm{NS}$ & $\mathrm{NS}$ & \\
CAL & & & & \\
PRP + ABBM & $9.9 \pm 1.7$ & $5.3 \pm 1.8$ & $4.6 \pm 1.7$ & $<0.001$ \\
ABBM & $9.6 \pm 1.9$ & $4.9 \pm 1.5$ & $4.7 \pm 1.6$ & $<0.001$ \\
$P$ value & $\mathrm{NS}$ & $\mathrm{NS}$ & $\mathrm{NS}$ & \\
\hline
\end{tabular}

$\mathrm{NS}=$ not statistically significant.

configuration. ${ }^{44-46}$ Recent findings ${ }^{45,46}$ have also indicated that contained type defects (i.e., 3-wall or narrow and deep defects) may provide a better environment for enhancing blood-clot stability compared to non-contained type defects (defects with missing bony walls or supraalveolar type defects), thus significantly influencing the outcomes.

Differences in the results might also be related to the study design (the present study had a parallelarm design, whereas the study by Hanna et al. ${ }^{21}$ was a split-mouth study and included smokers). Moreover, the posthealing evaluation period was longer in this study compared to previous ones (i.e., 6 months) 20,21 and included monthly recall appointments consisting of reinforcement of oral hygiene measures and professional supragingival tooth cleaning. Because PRP may influence the early phases of wound healing, it may be speculated that this initial advantage might be equalized after a longer period of time (1 year). ${ }^{13-16}$ Another possible explanation for the differences between the reported findings might be related to differences in the methods used PRP volumes prepared with the technique used in this study contain a mean platelet count value of 2,520 $\times$ $10^{3} / \mu \mathrm{l}$ and high mean concentration values of growth factors (i.e., $295 \mathrm{ng} / \mu \mathrm{l}$ PDGF-AB and $500 \mathrm{ng} / \mu \mathrm{l} \mathrm{TGF}$ $\beta 1) .{ }^{48}$ Furthermore, it should also be realized that the present study did not have a statistical power to rule out the possibility of a difference between the two groups, and thus, a much higher number of defects would be needed to detect an eventual difference between the treatments. ${ }^{49}$

Another aspect that should be taken into consideration when discussing the present results is the lack of a placebo instead of PRP. The use of a placebo may be desirable to adequately evaluate the potential of PRP, but the present study included the use of a grafting material for both groups, which yielded excellent outcomes. Thus, it seems likely that, even with the use of a placebo, the detection of significant differences between the two groups might have been difficult.

The positive outcomes obtained with ABBM alone are in line with findings from previous studies ${ }^{32,42,43}$ that have failed to demonstrate significant differences between treatment with ABBM alone versus DFDBA alone or a combination of an enamel matrix derivative and ABBM. These results seem to indicate that, at least from a clinical point of view, treatment with $\mathrm{PRP}+\mathrm{ABBM}$ may not significantly improve the results obtained with $A B B M$ alone. When interpreting the results obtained in the PRP + ABBM group, it should be kept in mind that the precise mechanism of PRP on periodontal regeneration is still not well understood, and until now, there is no evidence demonstrating periodontal regeneration in human intrabony defects following this approach. In this context, findings from human histologic case reports have also provided evidence of cementum, periodontal ligament, and bone formation following treatment with ABBM alone. ${ }^{31,37}$ Thus, the clinical improvements obtained with ABBM alone may represent a clinical improvement and, at least to some extent, a regenerative type of healing. Conversely, the present results need to be interpreted with caution because the possibility for PRP to show any beneficial effect when used in combination with ABBM might have been masked due to the fact that 
treatment with ABBM alone resulted in significant improvements.

\section{CONCLUSIONS}

Within its limits, the present study showed that 1) significant PD reductions and CAL gains were found 1 year after regenerative surgery with PRP + ABBM and $\mathrm{ABBM}$ alone, and 2) the use of PRP failed to improve the results obtained with ABBM alone.

\section{ACKNOWLEDGMENTS}

The study was funded by the Departments of Periodontology and Oral and Maxillofacial Surgery, Semmelweis University. The authors report no conflicts of interest related to this study.

\section{REFERENCES}

1. Karring T, Lindhe J, Cortellini P. Regenerative periodontal therapy. In: Lindhe J, Karring T, Lang NP, eds. Clinical Periodontology and Implant Dentistry. Copenhagen: Blackwell Munksgaard; 2003:650-704.

2. Caffesse RG, Quinones CR. Polypeptide growth factors and attachment proteins in periodontal wound healing and regeneration. Periodontol 2000 1993;1:69-79.

3. Giannobile WV, Finkelman RD, Lynch SE. Comparison of canine and non-human primate animal models for periodontal regenerative therapy. Results following a single administration of PDGF/IGF-I. J Periodontol 1994;65:1158-1168.

4. Lynch SE, Williams RC, Polson AM. A combination of platelet-derived and insulin-like growth factors enhances periodontal regeneration. J Clin Periodontol 1989;16:545-548.

5. Lynch SE, de Castilla GR, Williams RC, et al. The effects of short-term application of a combination of plateletderived and insulin-like growth factors on periodontal wound healing. J Periodontol 1991;62:458-467.

6. Rutherford RB, Niekrash CE, Kennedy JE, Charette $M F$. Platelet-derived and insulin-like growth factors stimulate regeneration of periodontal attachment in monkeys. J Periodontal Res 1992;27:285-290.

7. Rutherford RB, Ryan ME, Kennedy JE, Tucker MM, Charrette MF. Platelet-derived growth factor and dexamethasone combined with a collagen matrix induce regeneration of the periodontium in monkeys. J Clin Periodontol 1993;20:537-544.

8. Wang HL, Pappert TD, Castelli WA, Chiego DJ Jr., Shyr Y, Smith BA. The effect of platelet-derived growth factor on the cellular response of the periodontium: An autoradiographic study on dogs. J Periodontol 1994; 65:429-436.

9. Nevins ML, Camelo M, Nevins M, Schenk RK, Lynch SE. Periodontal regeneration in humans using recombinant human platelet-derived growth factor-BB (rhPDGF-BB) and allogeneic bone. J Periodontol 2003;74:1282-1292.

10. Camelo M, Nevins ML, Schenk RK, Lynch SE, Nevins $M$. Periodontal regeneration in human Class II furcations using purified recombinant human platelet-derived growth factor BB (rhPDGF-BB) with bone allograft. Int $J$ Periodontics Restorative Dent 2003;23: 213-225.

11. Howell TH, Fiorellini JP, Paquette DW, Offenbacher S, Giannobile WV, Lynch SE. A phase I/II clinical trial to evaluate a combination of recombinant human insulin-like growth factor-I in patients with periodontal disease. J Periodontol 1997;68:1186-1193.

12. Nevins M, Giannobile WV, McGuire MK, et al. Plateletderived growth factor stimulates bone fill and rate of attachment level gain: Results of a large multicenter randomized controlled trial. J Periodontol 2005;76: 2205-2215.

13. Marx RE, Carlson ER, Eichstaedt RM, Schimmele SR, Strauss JE, Georgeff KR. Platelet-rich plasma. Growth factor enhancement for bone grafts. Oral Surg Oral Med Oral Pathol Oral Radiol Endod 1998; 85:638-646.

14. Tözüm TF, Demiralp B. Platelet-rich plasma: A promising innovation in dentistry. $J$ Can Dent Assoc 2003;69:664.

15. Sanchez AR, Sheridan PJ, Kupp LI. Is platelet-rich plasma the perfect enhancement factor? A current review. Int J Oral Maxillofac Implants 2003;18:93103.

16. Marx RE. Platelet-rich plasma: Evidence to support its use. J Oral Maxillofac Surg 2004;62:489-496.

17. de Obarrio JJ, Araúz-Dutari JI, Chamberlain TM, Croston A. The use of autologous growth factors in periodontal surgical therapy: Platelet gel biotechnology - Case reports. Int J Periodontics Restorative Dent 2000;20:486-497.

18. Camargo PM, Lekovic V, Weinlaender M, Vasilic $N$, Madzarevic M, Kenney EB. Platelet-rich plasma and bovine porous bone mineral combined with guided tissue regeneration in the treatment of intrabony defects in humans. J Periodontal Res 2002;37:300306.

19. Camargo PM, Lekovic V, Weinlaender M, Vasilic N, Madzarevic M, Kenney EB. A reentry study on the use of bovine porous bone mineral, GTR, and platelet-rich plasma in the regenerative treatment of intrabony defects in humans. Int $J$ Periodontics Restorative Dent 2005;25:49-59.

20. Lekovic V, Camargo PM, Weinlaender M, Vasilic N, Kenney EB. Comparison of platelet-rich plasma, bovine porous bone mineral, and guided tissue regeneration versus platelet-rich plasma and bovine porous bone mineral in the treatment of intrabony defects: A reentry study. J Periodontol 2002;73:198-205.

21. Hanna R, Trejo PM, Weltman RL. Treatment of intrabony defects with bovine-derived xenograft alone and in combination with platelet-rich plasma: A randomized clinical trial. J Periodontol 2004;75:1668-1677.

22. Okuda K, Tai H, Tanabe K, et al. Platelet-rich plasma combined with a porous hydroxyapatite graft for the treatment of intrabony periodontal defects in humans: A comparative controlled clinical study. J Periodontol 2005; 76:890-898.

23. Piemontese M, Aspriello SD, Rubini C, Ferrante L, Procaccini $M$. Treatment of periodontal intrabony defects with demineralised freeze-dried bone allograft in combination with platelet-rich plasma: A comparative clinical trial. J Periodontol 2008;79:802-810.

24. Christgau M, Moder D, Wagner J, et al. Influence of autologous platelet concentrate on healing in intrabony defects following guided tissue regeneration therapy: A randomized prospective clinical splitmouth study. J Clin Periodontol 2006;33:908-921.

25. Yassibag-Berkman Z, Tuncer O, Subasioglu T, Kantarci A. Combined use of platelet-rich plasma and bone grafting with or without guided tissue regeneration in 
the treatment of anterior interproximal defects. $J$ Periodontol 2007;78:801-809.

26. Demir B, Sengün D, Berberoglu A. Clinical evaluation of platelet-rich plasma and bioactive glass in the treatment of intra-bony defects. J Clin Periodontol 2007;34:709-715.

27. Döri F, Huszár T, Nikolidakis D, Arweiler NB, Gera I, Sculean A. Effect of platelet-rich plasma on the healing of intrabony defects treated with an anorganic bovine bone mineral and expanded polytetrafluoroethylene membranes. J Periodontol 2007;78: 983-990.

28. Döri F, Huszár T, Nikolidakis D, Arweiler NB, Gera I, Sculean AA. Effect of platelet-rich plasma on the healing of intra-bony defects treated with a natural bone mineral and a collagen membrane. J Clin Periodontol 2007;34:254-261.

29. Döri F, Huszár T, Nikolidakis D, et al. Effect of plateletrich plasma on the healing of intrabony defects treated with a $\beta$-tricalcium phosphate and expanded polytetrafluoroethylene membranes. J Periodontol 2008;79: 660-669.

30. Skoglund A, Hising P, Young C. A clinical and histologic examination in humans of the osseous response to implanted natural bone mineral. Int J Oral Maxillofac Implants 1997;12:194-199.

31. Camelo M, Nevins M, Schenk R, et al. Clinical, radiographic, and histologic evaluation of human periodontal defects treated with Bio-Oss and Bio-Gide. Int J Periodontics Restorative Dent 1998;18:321-331.

32. Richardson CR, Mellonig JT, Brunsvold MA, et al. Clinical evaluation of Bio-Oss: A bovine-derived xenograft for the treatment of periodontal osseous defects in humans. J Clin Periodontol 1999;26:421-428.

33. Mellonig JT. Human histologic evaluation of a bovinederived xenograft in the treatment of periodontal osseous defects. Int $J$ Periodontics Restorative Dent 2000;20:19-29.

34. Paolantonio M. Combined periodontal regenerative technique in human intrabony defects by collagen membranes and anorganic bovine bone. A controlled clinical study. J Periodontol 2002;73:158-166.

35. Sculean A, Berakdar M, Chiantella GC, et al. Healing of intrabony defects following treatment with a bovinederived xenograft and collagen membrane. A controlled clinical study. J Clin Periodontol 2003;30:73-80.

36. Sculean A, Stavropoulos A, Windisch P, Keglevich T, Karring T, Gera I. Healing of human intrabony defects following regenerative periodontal therapy with a bovine-derived xenograft and guided tissue regeneration. Clin Oral Investig 2004;8:70-74.

37. Sculean A, Windisch P, Keglevich T, Chiantella GC, Gera I, Donos N. Clinical and histological evaluation of human intrabony defects treated with an enamel matrix protein derivative combined with a bovine-derived xenograft. Int J Periodontics Restorative Dent 2003;23: 47-55.
38. Armitage GC. Development of a classification system for periodontal diseases and conditions. Ann Periodontol 1999;4:1-6.

39. Löe H. The gingival index, the plaque index and the retention index systems. J Periodontol 1967;38:610616.

40. Tonetti MS, Pini Prato GP, Cortellini P. Effect of cigarette smoking on periodontal health following GTR in infrabony defects. A preliminary retrospective study. $J$ Clin Periodontol 1995;22:229-234.

41. Fleiss J. The Design and Analysis of Clinical Experiments. New York: John Wiley \& Sons; 1986:120148.

42. Sculean A, Chiantella GC, Windisch P, Gera I, Reich E. Clinical evaluation of an enamel matrix protein derivative (Emdogain) combined with a bovine-derived xenograft (Bio-Oss) for the treatment of intrabony periodontal defects in humans. Int $J$ Periodontics Restorative Dent 2002;22:259-267.

43. Scheyer ET, Velasquez-Plata D, Brunsvold MA, Lasho DJ, Mellonig JT. A clinical comparison of a bovinederived xenograft used alone and in combination with enamel matrix derivative for the treatment of periodontal defects in humans. J Periodontol 2002;73: 423-432.

44. Rosling B, Nyman S, Lindhe J. The effect of systematic plaque control on bone regeneration in infrabony pockets. J Clin Periodontol 1976;3:38-53.

45. Cortellini P, Tonetti MS. Clinical performance of a regenerative strategy for intrabony defects: Scientific evidence and clinical experience. J Periodontol 2005; 76:341-350.

46. Sculean A, Nikolidakis D, Schwarz F. Regeneration of periodontal tissues: Combination of barrier membranes and grafting materials - Biological foundation and preclinical evidence. A systematic review. J Clin Periodontol 2008;35(Suppl. 8):106-116.

47. Weibrich G, Kleis WK, Hafner G. Growth factor levels in the platelet-rich plasma produced by 2 different methods: Curasan-type PRP kit versus PCCS PRP system. Int J Oral Maxillofac Implants 2002;17:184190.

48. Appel TR, Potzsch B, Muller J, von Lindern JJ, Berge SJ, Reich RH. Comparison of three different preparations of platelet concentrates for growth factor enrichment. Clin Oral Implants Res 2002;13:522-528.

49. Gunsolley JC, Elswick RK, Davenport JM. Equivalence and superiority testing in regeneration clinical trials. J Periodontol 1998;69:521-527.

Correspondence: Dr. Anton Sculean, Department of Periodontology, University of Bern, Freiburgstrasse 7, 3008 Bern, Switzerland. Fax: 41-31-632-49-15; e-mail: anton. sculean@zmk.unibe.ch.

Submitted January 29, 2009; accepted for publication May 17, 2009. 